\title{
Gingivoestomatitis herpética severa en paciente con cardiopatía congénita; reporte de caso clínico
}

\author{
Marlette Esthefanía Domínguez, ${ }^{1}$ \\ Ingrid Hoffman, ${ }^{2}$ \\ Kadixy Pérez Kadixy, ${ }^{1}$ \\ Darling Acosta. ${ }^{1}$
}

\section{Resumen}

La gingivoestomatitis herpética corresponde a la manifestación primaria de la infección por virus herpes simple tipo I que se presenta con mayor frecuencia en lactantes mayores y preescolares. Objetivo: describir abordaje y manejo de gingivo estomatitis herpética en una paciente con cardiopatía congénita y cuadro de desnutrición severa. El caso se refiere a paciente femenina de 16 meses de edad a quien le fue realizado anamnesis, examen clínicoe interconsultas con servicios de pediatría, patología, medicina bucal, infectología. El diagnóstico incluyó comunicación intraventricular, desnutrición severa y gingivoestomatitis herpética. Se realizó tratamiento paliativo para el dolor, terapia antiviral (aciclovir en suspensión 1 cc cada 6 horas por 7 días) y tratamiento tópico (sucralfato en suspensión $1 \mathrm{~g} / 5 \mathrm{ml}$ mezclado en partes iguales con cetirizina en suspensión. $5 \mathrm{mg} / 5 \mathrm{ml}$, 3 veces al día directamente sobre las lesiones) durante 14 días logrando reducción de la sintomatologia. Conclusiones: el correcto manejo multidisciplinario permitió lograr disminución en tamaño y número de las lesiones en cavidad oral, orientación dietética y canalización apropiada.

Palabras clave: Gingivoestomatitis, Herpes, vesículas, cardiopatía.

Caso clinico

\section{Gengivoestomatite herpética grave em paciente com cardiopatia congênita; relato de caso clínico}

\section{Resumo}

A gengivoestomatite herpética corresponde à manifestação primária da infecção pelo vírus herpes simplex tipo I, que ocorre com mais frequência em bebês e em idade pré-escolar. Objetivo: descrever a abordagem e o tratamento da estomatite herpética gengival em um paciente com cardiopatia congênita e desnutrição grave. $\mathrm{O}$ caso refere-se a uma paciente de 16 meses de idade, submetida a anamnese, exame clínico

${ }^{1}$ Estudiante de Postgrado de Odontopediatría. Facultad de Odontología, Universidad de Carabobo, Valencia, Venezuela.

${ }^{2}$ Profesor especialista en Odontopediatría. Facultad de odontología, universidad de Carabobo, Valencia, Venezuela. 
e interconsultas com serviços de pediatria, patologia, medicina bucal, infectologia. $\mathrm{O}$ diagnóstico incluiu comunicação intraventricular, desnutrição grave e gengivostomatite herpética. Foram realizados tratamento paliativo para dor, terapia antiviral (suspensão de aciclovir 1cc a cada 6 horas por 7 dias) e tratamento tópico (suspensão de sucralfato $1 \mathrm{~g} / 5 \mathrm{ml}$ misturado em partes iguais com suspensão de cetirizina 5mg /
$5 \mathrm{ml}, 3$ vezes ao dia diretamente. lesões) por 14 dias, alcançando redução dos sintomas. Conclusões: o correto manejo multidisciplinar permitiu diminuir o tamanho e o número de lesões na cavidade oral, orientação alimentar e canalização adequada.

Palavras chaves: Gengivoestomatite, Herpes, vesículas, doença cardíaca.

Case report

\section{Severe herpetic gingivostomatitis in a patient with congenital heart disease; clinical case report}

\begin{abstract}
Herpetic gingivostomatitis is the primary manifestation of herpes simplex virus type I infection, common in older infants and preschoolers. Objective: to describe the approach and management of herpetic stomatitis in a patient with congenital heart disease and severe malnutrition. The case refers to a 16-month-old female patient who underwent an anamnesis, clinical examination, and inter-consultations with pediatric, pathological, oral medicine services, and Diagnosis included intraventricular communication, severe malnutrition,
\end{abstract}

\section{Introducción}

La gingivoestomatitis herpética corresponde a la manifestación primaria de la infección por virus herpes simple que es más común en lactantes mayores y preescolares. Representa el 1,2\% de las infecciones orales, faciales y oculares. ${ }^{1}$ Pertenece al grupo de lesiones vesículo ampollares altamente dolorosas que se distribuyen and herpetic gingivostomatitis. Palliative treatment for pain, antiviral therapy (acyclovir suspension 1cc every 6 hours for 7 days) and topical treatment (sucralfate suspension $1 \mathrm{~g} / 5 \mathrm{ml}$ mixed in equal parts with cetirizine suspension 5mg / $5 \mathrm{ml}, 3$ times a day directly, were performed. about injuries) for 14 days. Conclusions: multidisciplinary, management, allowed to obtain, clinical diagnosis and establish a treatment plan with positive outcome,decreasing oral cavity dietary guidance and appropriate channeling.

Key words: Gingivostomatitis, vesicles, heart disease.

ampliamente en la mucosa bucal, encías, lengua, paladar, carrillo y garganta con una duración de 10 a 12 días cursando con cuadros febriles y adenopatías. ${ }^{1}$

En casos severos dichas lesiones vesiculares se unen transformándose en ulceras mayores que combinadas con la disminución en la higiene bucal, en la ingesta de líquidos y alimentos agravan el 
cuadro clínico originando deshidratación y desnutrición.

Por otra parte, la cardiopatía congénita más frecuente es la comunicación interventricular (CIV) la cual representa un $20 \%$ de todas las cardiopatías congénitas con una prevalencia de $1-3,5$ de 1000 nacidos vivos. ${ }^{2}$ Se trata de un orificio en el tabique interventricular que puede encontrarse en cualquier punto del mismo, ser único o múltiple con tamaño y forma variable. Las CIV medianas pueden desarrollar síntomas en las primeras semanas de vida; aumento de trabajo respiratorio, sudoración excesiva debido al tono simpático aumentado y fatiga con la alimentación, lo que compromete la ingesta calórica. ${ }^{3}$ Por lo que se debe realizar una valoración nutricional de forma precoz y rutinaria para evitar cuadros de malnutrición.

La atención oportuna de infecciones virales con manifestación bucales en pacientes con cardiopatías congénitas evita el riesgo de aumento de severidad de las lesiones y disminuye las posibilidades de complicaciones cardiacas asociadas a infecciones virales previas como la miocarditis aguda, fallo agudo, shock cardiogénico, arritmias o miocardiopatía dilatada, miocarditis y pericarditis. $^{3}$ Son muchos los profesionales de la odontología que al estar frente a un GIH (gingivoestomatitis herpética) manejan el protocolo de atención, sin embargo al encontrarla contigua a otro tipo de patologías de base como lo es cardiopatía y/o desnutrición pueden surgir dudas sobre las acciones a tomar. El propósito de este reporte es conocer el manejo interdisciplinario de gingivoestomatitis herpética severa en paciente con cardiopatía congénita.

\section{Descripción del caso}

Previa autorización del representante a través de un consentimiento informado avalado por la comisión coordinadora del Postgrado de Odontopediatría de la Universidad de Carabobo se procedió a la documentación, tratamiento y posterior publicación.

Se trata de paciente femenina lactante mayor de 16 meses natural y procedente de Valencia, Venezuela, que acude al postgrado de Odontopediatría Universidad de Carabobo refiriendo cuadro febril y dificultad para alimentarse. Los antecedentes médicos incluyen comunicación interventricular sub aórtica mediana sin control clínico ni tratamiento por parte de cardiología posterior al diagnóstico.

En los 15 días previos requirió hospitalización durante 7 días por impétigo no ampolloso con celulitis en región occipital derecha con tratamiento antimicrobiano de cefalotina IV por 6 días.

La valoración antropométrica revelo peso de $5.5 \mathrm{~kg}$ y talla $65 \mathrm{~cm}$ ubicándola por debajo de un percentil 5 .

Al examen extraoral se observan cicatrices en región occipital derecha consecuencia del impétigo no ampolloso (Figura 1). 


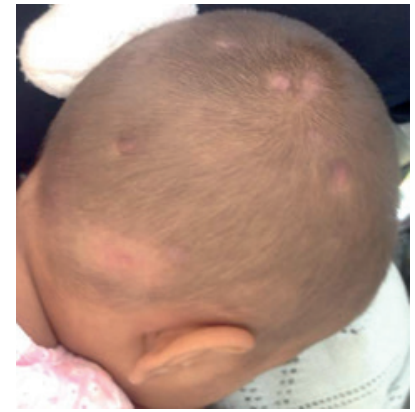

Figura 1. Al examen extraoral se observan cicatrices en región occipital derecha consecuencia del impétigo no ampolloso.
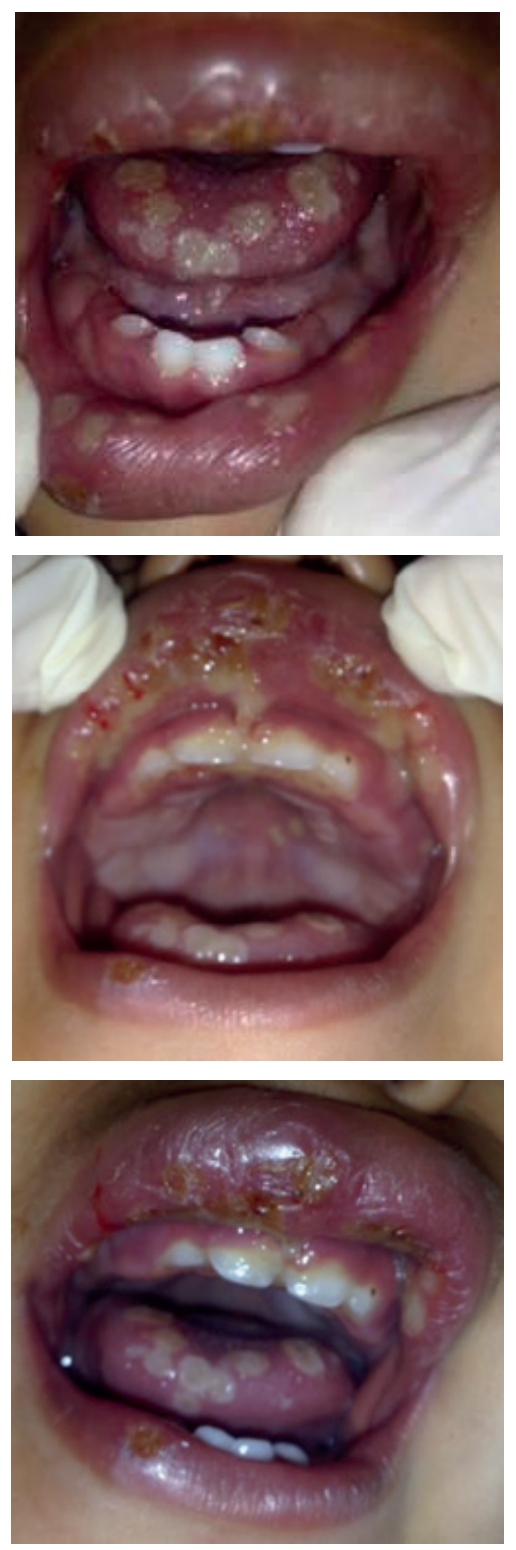

Figura 2. Examen intraoral.
Al examen intraoral (Figura 2) se observan múltiples lesiones vesiculares y ampollares en labio superior e inferior, úlceras mayores y menores en cara dorsal de la lengua y en paladar duro, sin ningún tipo de tratamiento.

Se realizaron interconsultas con servicio de patología, medicina bucal e infectología de la Ciudad Hospitalaria Enrique Tejera (CHET), se realizan exámenes de VIH (-) y se presume de inmunosupresión primaria. Basados en los hallazgos clínicos y antecedentes médicos se obtiene un diagnóstico presuntivo de gingivoestomatitis herpética. En conjunto con infectología se indica terapia antiviral con aciclovir en suspensión 1cc cada 6 horas por 7 días. Se aplicó tratamiento tópico sucralfato en suspensión $1 \mathrm{~g} / 5 \mathrm{ml}$ mezclado en partes iguales con cetirizina ensuspensión. $5 \mathrm{mg} / 5 \mathrm{ml}$, aplicándolo 3 veces al día directamente sobre las lesiones por 14 días. Se realizó profilaxis antimicrobiana con amoxicilina en suspensión $400 \mathrm{mg} / 5$ cc, 2cc cada 8 horas por 7 días.

Evolución clínica: Reevaluación clínica a los 15 días post tratamiento (Figura $3 a, 3 b, 3 c)$ se observa disminución en número, tamaño y severidad de las lesiones, ausencia de cuadros febriles con aumento en apetito.

Se refiere paciente a servicio de cardiología para evaluación y tratamiento de comunicación intraventricular sub aórtica; nutricionista para orientación dietética debido al cuadro de desnutrición severa persistente y servicio de inmunología para tratamiento de inmunosupresión primaria. 

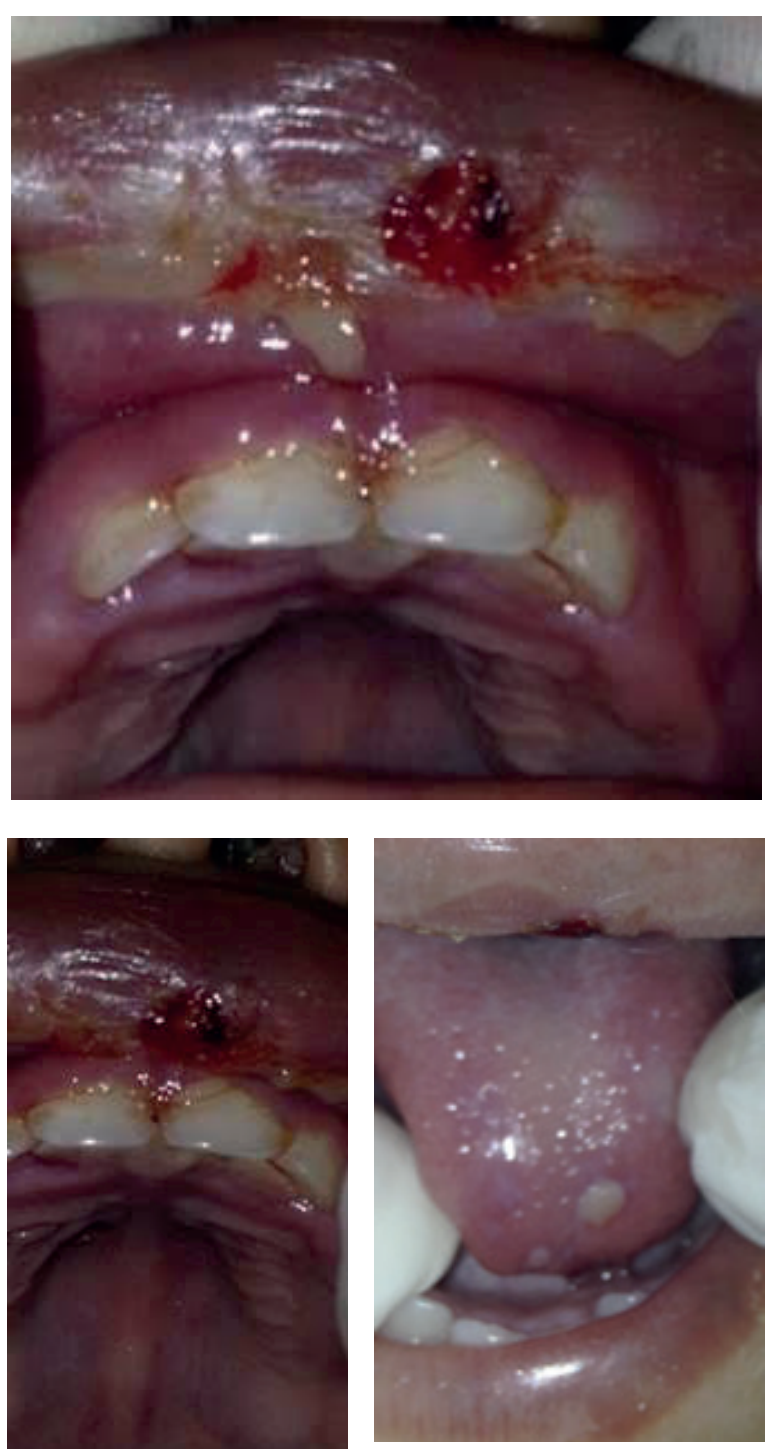

Figura 3. Reevaluación clínica.

En este caso clínico el desconocimiento por parte del representante, las múltiples condiciones sistémicas de base y la severidad de las lesiones corroboran estar frente un cuadro de inmunosupresión primaria consecuencia de la desnutrición severa originada por la alta demanda calórica que exige la CIV.

\section{Discusión}

Se ha descrito que la CIV puede asociarse con desnutrición energético-proteicay que, al ser así, en presencia de debilitamiento del sistema inmune puede aumentar el riesgo de infecciones. ${ }^{4}$

El caso presentado había estado previamente hospitalizada por presentar impétigo, y posteriormente acude a consulta de odontopediatría con infección por Virus Herpes Simple tipo 1. Siendo así, el abordaje no sólo fue dirigido al manejo de las lesiones orales mediante terapias paliativas del dolor, sino que incluyó la correcta canalización para realización de interconsultas en las especialidades requeridas como lo es el servicio de cardiología y nutrición, así como a la orientación y guía del representante.

Las infecciones virales representan la causa infecciosa más importante de complicaciones cardiacas como lo son la miocarditis y la pericarditis. La existencia de inmunosupresión de cualquier tipo favorece la pericarditis ocasionada porcitomegalovirus y en menor medida por virus del herpes simple, virus varicela zoster y virus de Epstein-Barr. ${ }^{5}$

Realizar la atención apropiada a paciente pediátrico que refiere cardiopatía de base combinado a cuadro de desnutrición advierte de un posible debilitamiento del sistema inmune lo que podría conllevar a cuadros clínicosmásseveroscaracterizados por múltiples lesiones vesiculares, sialorrea, halitosis, adenopatías cervicales o submentonianas. La disminución en la ingesta calórica es el factor más reconocible como causa de desnutrición. ${ }^{6}$ Por ello la dificultad para ingerir alimentos causada por la presencia de vesículas altamente dolorosas extensivas a labios, encías, mucosas, paladar duro y lengua advierte sobre una complicación en el cuadro nutricional. 
Los niños con cardiopatía congénita necesitan mayor aporte de calorías por kilogramo de peso y día. En el caso presentado, la paciente presentó diagnóstico de desnutrición crónica ubicándose en un percentil inferior al 5 . Esta condición puede relacionarse con inmunosupresión, siendo que la paciente presentó antecedente de impétigo previamente.

En este reporte clínico la dieta blanda, la terapia propuesta por el servicio odontopediatría e infectología con acliclovir y antimicrobiana fueron fundamentales. La involución de dichas lesiones va de 10 a 15 días por lo que el manejo efectivo de estos pacientes y sus representantes involucra más un cambio de actitud que de técnica. Las actitudes importantes son serenidad, comprensión y paciencia. ${ }^{7}$

Es importante adjudicar el rol del Odontopediatra en el tratamiento integral de los pacientes pediátricos que acuden con patologías orales asociados con otras condiciones sistémicas. En el presente caso, el odontopediatra al momento de la consulta por medio de las lesiones bucales pudo constatar que la representante presentaba desconocimiento y falta de compromiso con respecto al cuidado apropiado de acuerdo con el estado de salud de su hija. Aunado a ello, pudo evidenciar dificultades en el seguimiento médico de la patología cardíaca de base debido probablemente a las limitaciones y carencias actuales de los servicios hospitalarios en Venezuela y de los accesos a exámenes complementarios.

Sin embargo, cabe destacar, el profesionalismo del equipo interdisciplinario conformado para la atención de esta paciente que permitió un correcto manejo mediante una exhaustiva anamnesis y examen clínico.

\section{Conclusión}

Siendo la GIH la infección por herpes simple más común en lactantes y preescolares es importante que todo odontólogo maneje el protocolo a ejecutar al encontrarse frente a esta.

El manejo profesional interdisciplinario en este caso permitió establecer un correcto diagnostico lo que permitió un efectivo plan de tratamiento disminuyendo en número y tamaño de las lesiones herpéticas.

El verdadero éxito en este reporte es demostrar la influencia y el alcance de la Odontopediatría, como parte del equipo interdisciplinario ya que logró motivar, orientar, educar y comprometer a la representante con la salud de su hija, así como canalizar a la paciente por los diversos servicios médicos.

\section{Referencias bibliográficas}

1. Chen C-K, Wu S-H, Huang Y-C. Herpetic gingivostomatitis with severe hepatitis in a previously healthy child. J Microbiol Immunol Infect. 2012; 45(4): 324-5.

2. Staikov I, Neyko V, Kazandjieva J, Tsankov N. Is herpes simplex a systemic disease? Dermatologic Clinics. 2015; 33: 551-555.

3. Camacho J, Contreras J, Díaz P, Franco J. Miocarditis en Pediatría. Rev. Colomb. Cardiol. 2017: 24(5): 496-504. 
4. Salinas Y, Millan R. Gingivoestomatitis hérpetica primaria. Conducta odontológica. Acta Odontol Venez. 2008; 46(2): 219-226

5. Bouza J, Martinez P, Rodriguez A. Patología del corazón de origen extracardíaco $(X)$. Enfermedades cardíacas de etiología vírica. Rev Esp Cardiol 1998; 7: 582-590

6. Pozas A, Salinas D, Vázquez A, Guadalupe M, Rivera G, Martínez H. Gingivoestomatitis herpética severa en el paciente con necesidad de cuidados especiales de salud: reporte de un caso. Rev. Mex Periodontol 2012: 3 (3): 109-113

7. Hernández H, PrattI, Rodríguez M, Rodríguez M. Oral lichen planus versus acute herpetic gingivostomatitis. Rev Ciencias Médicas 2013; 17(6): 188-195

Recibido: 25/04/2019

Aceptado: 01/04/2020

Correspondencia: Marlette Esthefania Dominguez Rodriguez correo: dominguezestefania@gmail.com 